\title{
Neuroendocrine Tumour of the Appendix in Pregnancy
}

\author{
Andrejs Vanags*,**, Ilze Strumfa*, Zane Simtniece*, Jānis Gardovskis*,** \\ *Riga Stradins University, Latvia \\ **Pauls Stradins Clinical University Hospital, Riga, Latvia
}

\begin{abstract}
Summary
Despite the fact that the appendix is one of the rarest anatomic localization of neuroendocrine tumours (NETs) in the digestive system, the appendicular neuroendocrine tumour (A-NET) remains among the most common tumours of the appendix. The A-NET usually presents as a small solitary lesion revealed only after pathological examination of appendix that has been surgically removed for acute appendicitis. Only 18 papers in the Pubmed database (1965-2012) are dedicated to A-NET in pregnancy. Here we present a well-documented case of A-NET in a pregnant lady.
\end{abstract}

Key words: pregnancy, appendix, neuroendocrine tumour.

\section{AIM OF THE DEMONSTRATION}

We present thoroughly documented case of A-NET of the appendix in a pregnant female in order to demonstrate a rare tumour in an unusual clinical setting.

\section{CASE REPORT}

A 24-year-old female with progressive $2^{\text {nd }}$ pregnancy of 35 weeks was admitted to the hospital due to dull pain in the epigastrium. There was no evidence of previous similar episodes. The ultrasonography (US) revealed slightly enlarged spleen reaching $14 \times 4.7 \mathrm{~cm}$ as the only abnormality. By foetal US, foetus corresponded to the gestational age of 34 weeks and 4 days. The laboratory investigations demonstrated low haemoglobin level $117 \mathrm{~g} / \mathrm{L}$ [laboratory reference interval 131-175 g/L] and increased white blood cell (WBC) count 12.9 $\times 10^{9} / \mathrm{L}\left[4.0-9.8 \times 10^{9} / \mathrm{L}\right]$. A surgeon consulted patient on the same day. Progressive pain in the lower part of abdomen was established by the second visit of surgeon on the next morning; a diarrhoea episode was also revealed. C-reactive protein (CRP) level was progressively increasing from $7.5 \mathrm{mg} / \mathrm{L}$ to $58.7 \mathrm{mg} / \mathrm{L}$ [0$5.0 \mathrm{mg} / \mathrm{L}]$. The indications for appendectomy were set up and the operation was performed by the McBurney laparotomy approach. No specific local findings were found during the exploration of the abdominal cavity. The appendix was compressed by the uterus; it was located behind the caecum. No palpable mass and no peritoneal fluid was revealed during the laparotomy. However, the apex of the appendix visually was slightly enlarged and the appendix was removed. The wound healed by primary intention without any local or general complications. After the operation, CRP level decreased to $19.5 \mathrm{mg} / \mathrm{L}$ and WBC count regressed to $5.4 \times 10^{9} / \mathrm{L}$. By histology, apical appendicular NET was revealed, measuring $1 \mathrm{~cm}$. The diagnosis was confirmed by positive expression of neuroendocrine markers synaptophysin and chromogranin A (Figure 1). The proliferation activity by Ki-67 was negligible $(0.3 \%)$. Oncologic council recommended repeated consultation after child-bearing, but any chemotherapy or extended surgery was considered not necessary.

\section{DISCUSSION}

The annual incidence of A-NETs is 2-3 cases per million with predominance in females and younger age group $(6,11,12,22)$ regardless of race $(12,14,16,17)$. A-NETs are discovered in 7/1000 of appendectomy specimens. The tumours are notable for their small size (15). A-NETs are the most common appendicular tumours accounting for more than $50 \%$ of primary appendicular neoplasms $(5,7,20,21)$. However, A-NETs constitute only $5 \%$ of gastrointestinal neuroendocrine tumours (13). Only few papers were found in the Pubmed literature reporting A-NET during pregnancy $(3,9,10,19)$. A-NET clinically can be difficult to distinguish from acute appendicitis due to the lack of specific clinical features $(4,15)$. Sometimes the symptoms mimic pregnancyrelated complications. Computed tomography scan, US and magnetic resonance imaging occasionally show the primary neoplasm and metastases. Surgery should be undertaken as soon as possible when the diagnosis is established. However, in the reviewed published papers, A-NET was established postoperatively in all cases $(1,22)$. The main goal is the resection of primary tumour and metastatic lymph nodes. A-NETs can be cured by appendectomy if the tumour is located at the tip of the appendix and the tumour diameter is less than $2 \mathrm{~cm}$. More aggressive surgical intervention including right hemicolectomy is indicated if tumour is larger than $2 \mathrm{~cm}$ in diameter, has deep mesoappendiceal invasion, and/or positive surgical margins $(2,8,18)$.

In conclusion, A-NET in pregnant female has similar clinical manifestations to acute appendicitis. Thus, clinicians should keep in mind the possibility of primary A-NET managing suspected acute appendicitis in pregnant female.

\section{Conflict of interest: None}




\section{REFERENCES}

1. Anderson JR, Wilson BG. Carcinoid tumours of the appendix // Br J Surg, 1985; 72:545 - 546

2. Bamboat ZM, Berger DL. Is right hemicolectomy for 2.0-cm appendiceal carcinoids justified? //Arch Surg, 2006; 141:349 - 352

3. Basham KL, Hajdu SI, Teichberg S, Menzin A. Adenocarcinoid tumor of the ovary diagnosed during pregnancy: A case report // J Reprod Med, 2000; 45(9):758 - 761

4. Swelstad BB, Brezina PR, Johnson CT, Resetkova N, Woo I, Kolp L. Primary infertility associated with neuroendocrine tumor (Carcinoid) of the appendix // Asian Pacific Journal of Reproduction, 2012; $1(2): 152-154$

5. Carr NJ, Sobin LH. Neuroendocrine tumors of the appendix // Semin Diagn Pathol, 2004; 21:108 119

6. Caplin ME, Buscombe JR, Hilson AJ, Jones AL, Watkinson AF, Burroughs AK. Carcinoid tumour // Lancet, 1998; 352:799-805

7. Connor SJ, Hanna GB, Frizelle FA. Appendiceal tumors: retrospective clinicopathologic analysis of appendiceal tumors from 7,970 appendectomies // Dis Colon Rectum, 1998; 41:75 - 80

8. Dall'Igna P, Ferrari A, Luzzatto C, Bisogno G, Casanova M, Alaggio R, Terenziani M, Cecchetto G. Carcinoid tumor of the appendix in childhood: the experience of two Italian institutions // J Pediatr Gastroenterol Nutr, 2005; 40:216-219

9. Durkin JW. Carcinoid tumor and pregnancy // Am J Obstet Gynecol, 1983; 145(6):757 - 761

10. Gökaslan H, Sişmanoğlu A, Kaya H, Durmuşoğlu F. Incidental carcinoid of appendix in cesarean section // Eur J Obstet Gynecol Reprod Biol, 2002; 104(1):76- 78

11. Godwin JD 2nd. Carcinoid tumors. An analysis of 2,837 cases // Cancer, 1975; 36:560 - 569

12. Hemminki K, Li X. Incidence trends and risk factors of carcinoid tumors: a nationwide epidemiologic study from Sweden // Cancer, 2001; 92:2204 2210

13. Kulke MH, Mayer RJ. Carcinoid tumors // N Engl J Med, 1999; 340:858 - 868

14. Kulke MH. Clinical presentation and management of carcinoid tumors // Hematol Oncol Clin North Am, 2007; $21(3): 433-455$
15. Korkontzelos I, Papanicolaou S, Tsimoyiannis I, Kitsiou E, Stefos T, Tsanadis G, Antoniou N. Large carcinoid tumor of the appendix during pregnancy // Eur J Obstet Gynecol Reprod Biol, 2005; $118(2)$ :255257

16. Maggard MA, O'Connell JB, Ko CY. Updated population-based review of carcinoid tumors // Ann Surg, 2004; 240:117 - 122

17. Modlin IM, Lye KD, Kidd M. A five-decade analysis of 13,715 carcinoid tumors // Cancer 2003; 97: 934 959

18. O'Donnell ME, Carson J, Garstin WI. Surgical treatment of malignant carcinoid tumours of the appendix // Int J Clin Pract, 2007; 61: 431 - 437

19. Pitiakoudis M, Kirmanidis $M$, Tsaroucha A, Christianakis E, Filippou D, Sivridis E. Carcinoid tumor of the appendix during pregnancy // J BUON, 2008; 13(2): $271-275$

20. Poiana C, Carsote M, Trifanescu R, Terzea D, Croitoru A. Case study of appendiceal carcinoid during pregnancy // J Med Life, 2012; 15;5(3):325 328

21. Sandor A, Modlin IM. A retrospective analysis of 1570 appendiceal carcinoids // Am J Gastroenterol, 1998; 93:422 - 428

22. Tchana-Sato V, Detry O, Polus M, Thiry A, Detroz B, Maweja S, Hamoir E, Defechereux T, Coimbra C, De Roover A, Meurisse M, Honoré P. Carcinoid tumor of the appendix: a consecutive series from 1237 appendectomies // World J Gastroenterol, 2006; 12(41):669- 701

Acknowledgement The present work was carried out within the frames of scientific project $\mathrm{Nr}$. 2013/0004/1DP/1.1.1.2.0/13/APIA/VIAA/020, supported by ESF.

\section{Adress:}

Andrejs Vanags,

Department of Surgery, Riga Stradns University,

Pilsonu Street 13, LV 1002, Riga, Latvia

E-mail: vanags314@inbox.lv 

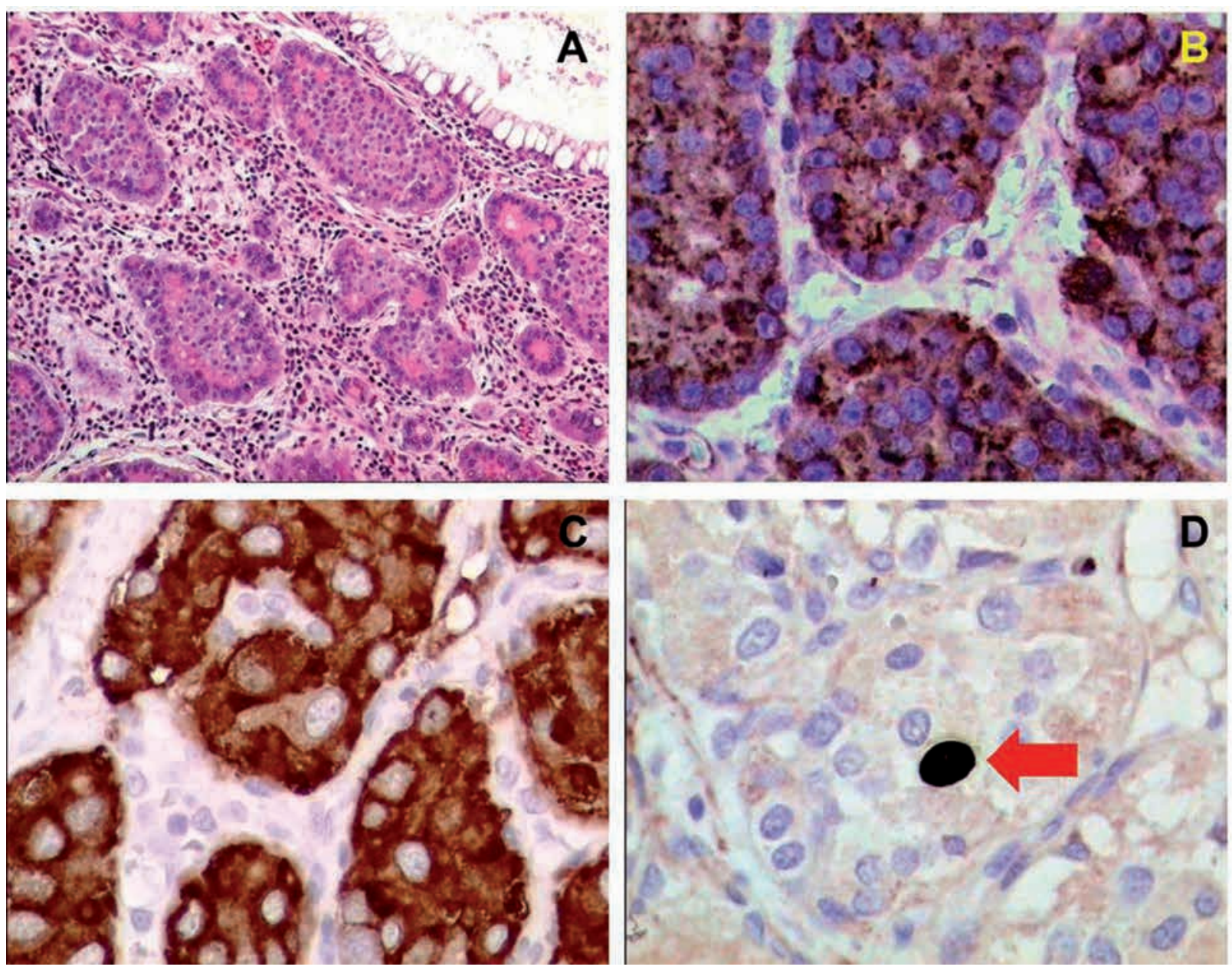

Fig.1. Histological and immunohist ochemical characteristics of the removed appendicular neuroendocrine tumour (NET). A, The overview of tissue structure. Haematoxylin - eosin, original magnification (OM) 100x. B. Intense granular cytoplasmic expression of chromogranin A. Immunoperoxidase (IP), antichromogranin A, OM 400x. C. Intense finely granular cytoplasmic expression of synaptophysin. IP, antisynaptophysin, OM 400x. D. Low proliferation fraction. Note the single positive nucleus (arrow). IP, anti-Ki-67, OM 400x 